\title{
Nurses and Television as Sources of Information Effecting Behavioral Improvement Regarding Liver Flukes in Nakhon Ratchasima Province, Thailand
}

\author{
Soraya J Kaewpitoon ${ }^{1,2,3 *}$, Natthawut Kaewpitoon ${ }^{1,3,4}$, Ratana Rujirakul ${ }^{1}$, \\ Parichart Wakkuwattapong ${ }^{1}$, Likit Matrakul ${ }^{3}$, Taweesak Tongtawee ${ }^{3}$, Ryan A \\ Loyd $^{1,2,3}$, Jun Norkaew ${ }^{4}$, Jirawoot Kujapun ${ }^{4}$, Wasugree Chavengkun ${ }^{4}$, Sukanya \\ Ponphimai $^{4}$, Poowadol Polsripradist ${ }^{5}$, Thawatchai Eksanti ${ }^{6}$, Tanida Phatisena ${ }^{6}$
}

\begin{abstract}
Background: Liver fluke infection with Opisthorchis viverrini and its associated cholangiocarcinoma constitute a serious problem in Thailand. Healthy behavior can decrease infection, therefore, the investigation of knowledge, attitude, and practice is need required in high risk areas. Objective: This study aimed to investigate the behavior and perceptions regarding liver fluke. Materials and Methods: A cross-sectional descriptive study was conducted in Chum Phuang district of Nakhon Ratchasima province, Thailand during July to November 2015. A total 80 participants who had screened with verbal screening test, stool examination, and ultrasonography, were purposive selected and completed a pre-designed questionnaire (Kruder-Richardon-20 $=0.80$, Cronbach's alpha coefficient $=0.82$ and 0.79). T-test, ANOVA, and Pearson correlation test were used for analyzed data. Results: The results reveal that $O$. viverrini infection was $1.25 \%$, and 3 patients had a dilated bile ducts. The participants had a high knowledge, attitude, and practice regarding liver fluke. The education, occupation, and income, were statistical significant to attitude regarding liver fluke. Nurses and television were the main sources of information regarding liver fluke, with statistical significance(p-value $<0.05)$. Knowledge was significantly associated with attitude and practice ( $p$-value $<0.05)$. Conclusions: Participants had good behavior regarding liver fluke. Improvement of knowledge and attitude is influenced to practical change regarding this carcinogenic fluke. In addition, nurse and television are the main information resources for key success in increasing people perception for disease prevention and control in this area.
\end{abstract}

Keywords: Nurses - television - health behavior - liver fluke - Thailand

Asian Pac J Cancer Prev, 17 (3), 1097-1102

\section{Introduction}

Liver fluke caused by Opisthorchis viverrini, is a serious problem in Thailand particularly in the northeast and north region (Kaewpitoon et al., 2008b; Sitthithaworn et al., 2012; Sripa et al., 2012; Wongsaroj et al., 2014; Kaewpitoon et al., 2015). Recently, the current status of liver fluke infection in Thailand was reported, a nationwide survey prevalent was $5.1 \%$. The highest of prevalent was found in the northeast $(9.2 \%)$ and followed by the north region (5.2\%). A total of 1,168 stool samples were obtained from 516 males and 652 females. Stool examination showed that $2.48 \%$ were infected with $O$. viverrini (Kaewpitoon et al., 2012c).

The experimental and epidemiological evidences strongly indicated that $O$. viverrini infection is the etiology of cholangiocarcinoma (CCA) (Thamavit et al., 1978; IARC, 1994; Sripa et al., 2007), and CCA has been reported that Thailand is the highest incident of the world (Green et al., 1991; Sripa, et al., 2007; Kaewpitoon et al., 2008a; Shin, et al., 2010). CCA was the caused of death in Thai population and found that CCA was ranked 4 in male and 5 in female (Sripa and Pairojkul, 2008). Mortality rate of CCA in Thailand was approximately $36.48 \%$ (Sripa et al., 2012). The mortality rate of CCA in Nakhon Ratchasima province, Thailand was ranked between 13.67-16.2 (Sripa et al., 2010).

Behavior on prevention and control of liver fluke infection are essential for decreasing the liver fluke infection. Previously studied indicated that knowledge, 
Soraya J Kaewpitoon et al

attitude, and practice related to liver fluke infection in rural communities (Kaewpitoon et al., 2007). Therefore, the current status of health behavior and information resources is need required. This study aimed to investigate the knowledge, attitude, and practice regarding liver fluke, including the information resources for this disease. The result may useful for further study and planning of liver fluke prevention and control.

\section{Materials and Methods}

A cross-sectional descriptive study was approved by the human research ethics committees of Suranaree University of Technology, 2015 (EC58-48). The study was conducted in Chum Phuang district, Nakhon Ratchasima province, Thailand during July to November 2015. Chum Phuang is a district in the eastern part of Nakhon Ratchasima province, neighboring districts are (from the north clockwise) Prathai, Mueang Yang and Lam Thamenchai of Nakhon Ratchasima Province, Lam Plai Mat of Buriram province, and Huai Thalaeng and Phimai of Nakhon Ratchasima again. The district is subdivided into 9 sub-districts, and 130 villages. This district is coverage areas $540.6 \mathrm{~km} 2$ (208.7 sq mi), and has 82,161 populations.

Multi-stage sampling was used to select the participants in this studied. Briefly, total of 29,385 populations from 82,311 populations was selected with criteria of aged $\geq 30$ years old. Populations were screened for CCA by using mini-verbal screening questionnaire contained the history with (1) opisthorchiasis; definitive diagnosed by medical doctor or related officers, (2) under-cooked fish consumption, (3) praziquantel used; given by medical doctor or related officers, (4) cholecystitis; definitive diagnosed by medical doctor or related officers, (5) relative family with cholangiocarcinoma, (6) naïve northeastern people, (7) agriculture, and (8) alcohol consumption. 80 participants (who had stool examination with MiniParasep SF concentration technique and abdomen ultrasonography), were participated and completed the pre-designed questionnaires. The questionnaire was comprised 5 domain included (1) demographic data; gender, age, education, agriculture, and income, (2) knowledge; 15 questions, (3) attitude; 20 questions, and (5) practice; 15 questions. Reliability and validity of questionnaire was analyzed, knowledge (KruderRichardon-20) $=0.80$, attitude and practice (Cronbach's alpha coefficient) $=0.82$ and 0.79 , respectively.

Evaluation of knowledge level was analyzed according to Bloom (1971), answer correct=1, incorrect=0, and interpreted to high level; $11-15$ points, moderate level; 6-10 points, 0-5 points; low level. Evaluation of attitude level was analyzed according to Likert (1932) with 3 choice (agree, not sure, dis-agree): positive question $=3,2,1$, negative question $=1,2,3$, and interpreted to good level; $48-60$ points, moderate level; $36-47$ points, and low level; 0-35 points. Evaluation of practical level was analyzed according to Best (1977) with 3 choice (frequently, sometimes, never): positive question=3,2,1, negative question $=1,2,3$, and interpreted to good level; 36-45 points, moderate level; 27-35 points, poor level;

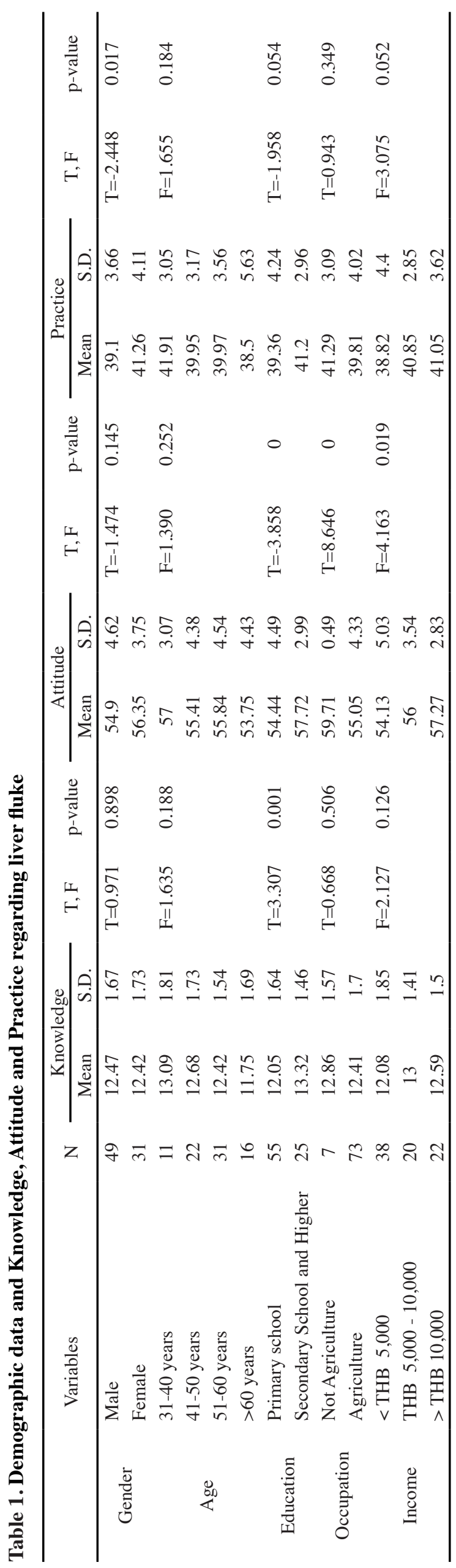


DOI:http://dx.doi.org/10.7314/APJCP.2016.17.3.1097

Nurses and Television as Information Sources for Behavioral Improvement Regarding Liver Flukes in Nakhon Ratchasima

Table 2. A comparison between perceive and information resources regarding liver fluke, classified by human

\begin{tabular}{|c|c|c|c|c|c|c|c|c|c|c|c|c|c|}
\hline \multirow{2}{*}{$\begin{array}{l}\text { Perceive } \\
\text { resources }\end{array}$} & \multirow{2}{*}{$\mathrm{n}$} & \multicolumn{4}{|c|}{ Knowledge } & \multicolumn{4}{|c|}{ Attitude } & \multicolumn{4}{|c|}{ Practice } \\
\hline & & mean & S.D. & $\mathrm{T}$ & p-value & mean & S.D. & $\mathrm{T}$ & p-value & mean & S.D. & $\mathrm{T}$ & p-value \\
\hline \multicolumn{14}{|c|}{ Head village } \\
\hline yes & 14 & 12.93 & 1.86 & 1.174 & 0.244 & 55.57 & 4.29 & 0.103 & 0.918 & 39.71 & 4.76 & -0.231 & 0.818 \\
\hline no & 66 & 12.35 & 1.64 & & & 55.44 & 4.38 & & & 39.98 & 3.8 & & \\
\hline \multicolumn{14}{|c|}{ Village health volunteer } \\
\hline yes & 48 & 12.67 & 1.6 & 1.419 & 0.16 & 55.9 & 4.35 & 1.095 & 0.277 & 40.23 & 3.53 & 0.806 & 0.423 \\
\hline no & 32 & 12.13 & 1.77 & & & 54.81 & 4.31 & & & 39.5 & 4.54 & & \\
\hline \multicolumn{14}{|c|}{ Public health officer } \\
\hline yes & 17 & 12.82 & 1.67 & 1.032 & 0.305 & 56 & 4.47 & 0.573 & 0.568 & 41.29 & 2.39 & 2.189 & 0.034 \\
\hline no & 63 & 12.35 & 1.69 & & & 55.32 & 4.33 & & & 39.57 & 4.22 & & \\
\hline \multicolumn{14}{|l|}{ Neighbor } \\
\hline yes & 4 & 13.25 & 2.06 & 0.975 & 0.333 & 58.25 & 2.22 & 1.324 & 0.189 & 37.75 & 6.75 & -1.137 & 0.259 \\
\hline no & 76 & 12.41 & 1.67 & & & 55.32 & 4.38 & & & 40.05 & 3.79 & & \\
\hline \multicolumn{14}{|c|}{ Member of sub-distric administrative organization } \\
\hline yes & 2 & 14 & 1.41 & 1.325 & 0.189 & 57 & 1.41 & 0.505 & 0.615 & 43.5 & 3.54 & 1.295 & 0.199 \\
\hline no & 78 & 12.41 & 1.68 & & & 55.42 & 4.39 & & & 39.85 & 3.94 & & \\
\hline \multicolumn{14}{|l|}{ Nurse } \\
\hline yes & 13 & 13.54 & 1.39 & 2.643 & 0.01 & 57.54 & 2.47 & 2.817 & 0.008 & 42.46 & 1.9 & 4.161 & 0.000 \\
\hline no & 67 & 12.24 & 1.66 & & & 55.06 & 4.52 & & & 39.45 & 4.07 & & \\
\hline \multicolumn{14}{|c|}{ Medical doctor } \\
\hline yes & 10 & 12.9 & 1.85 & 0.903 & 0.369 & 57.2 & 3.36 & 1.361 & 0.178 & 40 & 2.83 & 0.053 & 0.958 \\
\hline no & 70 & 12.39 & 1.66 & & & 55.21 & 4.43 & & & 39.93 & 4.11 & & \\
\hline
\end{tabular}

0-26 points. Descriptive and analytical statistics were used for analyzed in this study. T-test and ANOVA were used for analyze the difference between demographic data, information resources and behavior. Pearson correlation test was used for analyzed the association of knowledge, attitude, and practice.

\section{Results}

The majorities of participants were male, age between 51-60 years old, education level of primary school, agriculture, and had income $<5,000$ baht. The infection rate of intestinal helminthes was $4.60 \%$, and it was classified to Strongyloides sterocalaris $2.5 \%, O$. viverrini $1.25 \%$, Hookworm $1.25 \%$, and Taenia spp (1.25\%). CCA was screened, 3 patients from 80 participants had a dilated bile ducts (figure 1). The participants had a high knowledge, good attitude, and good practice regarding liver fluke.

Knowledge was statistical significant different in the educational level $(\mathrm{T}=3.307, \mathrm{p}$-value $=0.001)$. The participants had a high knowledge, attitude, and practice regarding liver fluke (Table 1). A comparison between demographic data and behavior regarding liver fluke was analyzed and found that attitude was statistical significant to educational level $(\mathrm{T}=3.858$, $\mathrm{p}$-value $=0.000)$, occupation $(\mathrm{T}=8.464, \mathrm{p}$-value $=0.000)$, and income $(\mathrm{T}=4.163$, $\mathrm{p}$-value $=0.019)$. In addition, practice was statistical significant to gender $(\mathrm{T}=-2.448, \mathrm{p}$-value $=0.017)($ Table 1$)$.

A comparison between perceive and information resources regarding liver fluke, was analyzed and found that nurse had a statistical significant to knowledge $(\mathrm{T}=2.643$, $\mathrm{p}$-value $=0.01)$, attitude $(\mathrm{T}=2.817, \mathrm{p}$-value $=0.008)$, and practice $(\mathrm{T}=4.161, \mathrm{p}$-value $=0.000)$. In addition, public

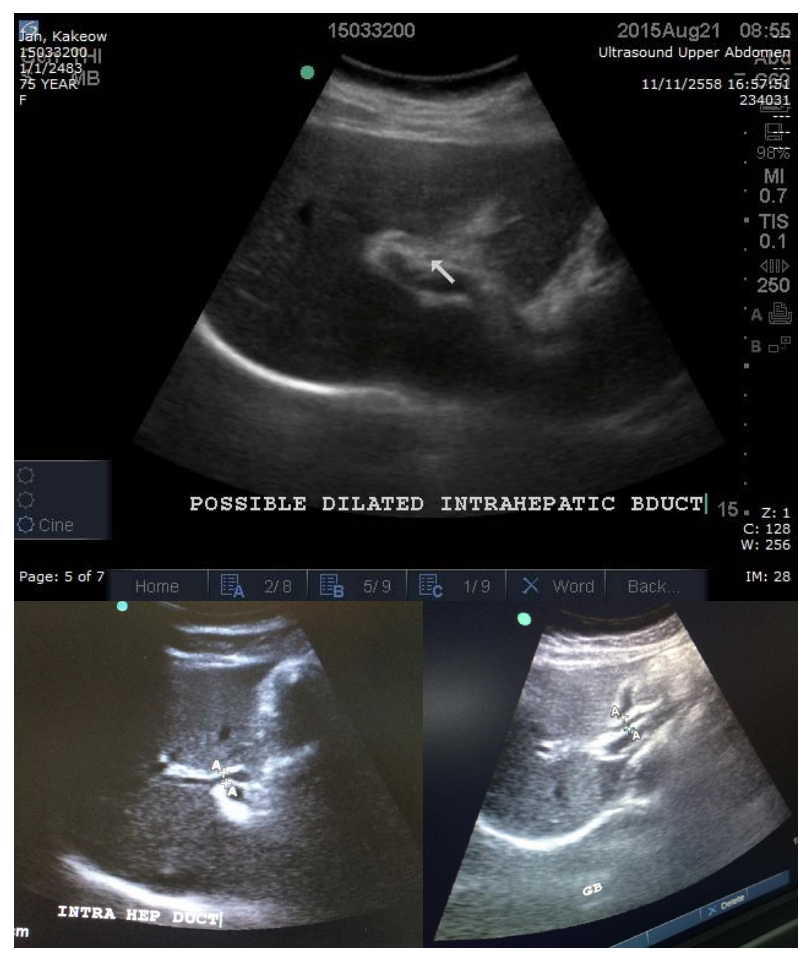

Figure 1. Bile Ducts with Dilation in 3 Patients from Chum Phuang district, Nakhon Ratchasima province, Thailand

health officer had a statistical significant to practice $(\mathrm{T}=2.189$, $\mathrm{p}$-value=0.034). Meanwhile, medical doctor, member of sub-district administrative organization, and neighbor, had not statistical significant to knowledge, attitude, and practice (Table 2). Television was a statistical significant to knowledge $(\mathrm{T}=2.377, \mathrm{p}$-value $=0.02)$, attitude $(\mathrm{T}=3.167, \mathrm{p}$-value $=0.002)$, and practice 
Table 3.A Comparison Between Perceive and Information Resources Regarding Liver Fluke, Classified by Media

\begin{tabular}{|c|c|c|c|c|c|c|c|c|c|c|c|c|c|}
\hline \multirow{2}{*}{$\begin{array}{l}\text { Perceive } \\
\text { resources }\end{array}$} & \multirow[b]{2}{*}{$\mathrm{n}$} & \multicolumn{4}{|c|}{ Knowledge } & \multicolumn{4}{|c|}{ Attitude } & \multicolumn{4}{|c|}{ Practice } \\
\hline & & mean & S.D. & $\mathrm{T}$ & $\begin{array}{c}\mathrm{p}- \\
\text { value }\end{array}$ & mean & S.D. & $\mathrm{T}$ & $\begin{array}{c}\mathrm{p}- \\
\text { value }\end{array}$ & mean & S.D. & $\mathrm{T}$ & $\begin{array}{c}\mathrm{p}- \\
\text { value }\end{array}$ \\
\hline \multicolumn{14}{|c|}{ Village news station } \\
\hline yes & 28 & 12.18 & 1.47 & -1.059 & 0.293 & 54.82 & 5.19 & -0.885 & 0.381 & 40.14 & 4.08 & 0.339 & 0.736 \\
\hline no & 52 & 12.6 & 1.79 & & & 55.81 & 3.82 & & & 39.83 & 3.92 & & \\
\hline \multicolumn{14}{|l|}{ Pamphlet } \\
\hline yes & 15 & 13.73 & 1.16 & 3.502 & 0.001 & 58.4 & 1.88 & 4.903 & 0 & 41.67 & 2.79 & 1.909 & 0.06 \\
\hline no & 65 & 12.15 & 1.65 & & & 54.78 & 4.47 & & & 39.54 & 4.09 & & \\
\hline \multicolumn{14}{|l|}{ Poster } \\
\hline yes & 3 & 14 & 1.73 & 1.643 & 0.104 & 59.67 & 0.58 & 7.322 & 0 & 42.67 & 1.15 & 1.222 & 0.226 \\
\hline no & 77 & 12.39 & 1.66 & & & 55.3 & 4.34 & & & 39.83 & 3.99 & & \\
\hline \multicolumn{14}{|l|}{ Television } \\
\hline yes & 35 & 12.94 & 1.73 & 2.377 & 0.02 & 57.03 & 2.94 & 3.167 & 0.002 & 41.06 & 2.61 & 2.445 & 0.017 \\
\hline no & 45 & 12.07 & 1.56 & & & 54.24 & 4.87 & & & 39.07 & 4.59 & & \\
\hline \multicolumn{14}{|l|}{ Newspaper } \\
\hline yes & 8 & 13.5 & 1.51 & 1.89 & 0.062 & 59.38 & 0.74 & 7.535 & 0 & 42.25 & 2.87 & 1.766 & 0.081 \\
\hline no & 72 & 12.33 & 1.67 & & & 55.03 & 4.36 & & & 39.68 & 3.99 & & \\
\hline \multicolumn{14}{|l|}{ Internet } \\
\hline yes & 3 & 13.67 & 1.53 & 1.281 & 0.204 & 59.67 & 0.58 & 7.332 & 0 & 43 & 1 & 1.374 & 0.173 \\
\hline no & 77 & 12.4 & 1.68 & & & 55.3 & 4.34 & & & 39.82 & 3.98 & & \\
\hline
\end{tabular}

Table 4. Correlation between Knowledge, Attitude and Practice Regarding Liver Flukes

\begin{tabular}{cccc}
\hline Variables & Knowledge & Attitude & Practice \\
\hline Knowledge & - & $0.377 * *$ & $0.261 *$ \\
Attitude & & - & $0.554 * *$ \\
Practice & & & - \\
\hline
\end{tabular}

*Correlation is significant at the 0.05 level (2-tailed); **Correlation is significant at the 0.01 level (2-tailed).

$(\mathrm{T}=2.445, \mathrm{p}$-value $=0.017)$. Pamphlet was a statistical significant to knowledge $(\mathrm{T}=3.502, \mathrm{p}$-value $=0.001)$ and attitude $(\mathrm{T}=4.903$, $\mathrm{p}$-value $=0.000)$. In addition, the internet $(\mathrm{T}=7.322$, $\mathrm{p}$-value $=0.000)$ and poster $(\mathrm{T}=7.322$, $\mathrm{p}$-value $=0.000$ ) were a statistical significant to attitude. Meanwhile, village news station and newspaper were not statistical significant to knowledge, attitude, and practice (Table 3).

A correlation between knowledge, attitude, and practice was analyzed and found that knowledge was statistical significant associated to attitude $(r=0.377$, $\mathrm{p}$-value $<0.05)$ and practice $(\mathrm{r}=0.261$, $\mathrm{p}$-value $<0.05)$. In addition, attitude was statistical significant associated to practice $(\mathrm{r}=0.554$, $\mathrm{p}$-value $<0.01)$ (Table 4$)$.

\section{Discussion}

Liver fluke infection caused by $O$. viverrini remains a major public health problem in many parts of Southeast Asia including Thailand, Lao PDR, Vietnam and Cambodia (IARC, 1994; Sripa et al., 2010). Infection is acquired by ingestion of undercooked cyprinoid's fish harboring infective metacercariae (Kaewkes 2003). Liver fluke is endemic among human populations in northeast and north Thailand, where the most common raw fish "Koi pla" is frequently consumed (Sadun 1955; Harinasuta and
Vajrasthira 1960; Wykoff et al., 1965; Preuksaraj et al., 1982). Recent study, we found that $O$. viverrini infection was $1.25 \%$, this result is lower than the previously survey in 2012. A total of 1,168 stool samples from Nakhon Ratchasima, Thailand were examined found that $2.48 \%$ were infected with $O$. viverrini and the infection rate was $2.78 \%$ in Chum Phuang district (Kaewpitoon et al., 2012c). The high mortality rate of CCA was reported in the northeast areas where found frequently of $O$. viverrini infection (Sripa et al., 2010). Mortality rate of liver cancer and $O$. viverrini infection rate in different regions of Thailand has been reported and found that Nakhon Ratchasima province has $13.67-16.2$ per 100,000 populations. Recent study shows that 3 patients from 80 participants had a dilated bile ducts, this finding indicates that CCA is still a problem in this area.

Improvement of health behavior regarding liver fluke prevention and control is need required. Here we investigated the behavior of rural people and found that the majorities of participants were male, age between 51-60 years old, education level of primary school, agriculture, and had income $<5,000$ baht. This recent results is similar to that several approaches for reducing opisthorchiasis-linked CCA. All participants were 3069 years of age. Of all the participants, more than $60 \%$ had regularly participated in activities to prevent CCA following health official advice. Age and health behavior to prevent CCA were factors associated with community participation for CCA $(\mathrm{p}<0.001)$ (Songserm et al., 2015). Our finding indicates that knowledge was statistic significant different in educational level, occupation, and income to attitude regarding liver fluke. Furthermore, gender was statistical significant to practice. This is similarly to that previously studied in Ubonratchathani province found that knowledge, attitude, and practice related to their demographic data particularly gender, 
education, and occupation (Kaewpitoon et al., 2007). Therefore, improvement of behavior regarding liver fluke, should be approaches in the group of male, age $>40$ years old, agriculture, and lowest income. A perceive of liver fluke severities, transmission, sign and symptom, related diseases, diagnosis, treatment, prevention and control, is a key for success to decrease the infection in risk areas. Other finding suggested that through participating in health education program. Participants learned the life cycle of liver fluke. They talked about this within their families, and communicated as well as cooperated with others to strengthen a network of a club concentrating on not eating raw fish. The communities and the Sub-district Administrative Organization supported the project. It is advisable to improve the behavior of participants in villages so that they became aware how to prevent and control liver fluke infection and therefore the development of CCA (Wongba et al., 2011). Recent study indicates that participant had a high perceive of information about this disease $(73.75 \%)$. The main resources were nurse and television particularly nurse had a statistical significant to improve people knowledge, attitude, and practice regarding liver fluke, followed by public health officer who can improve the practicum of people. Therefore, cooperation between nurse and public health officer are useful for increase the healthy practicum regarding liver fluke prevention and control. Furthermore, television was the main information resources regarding liver fluke, followed by pamphlet, internet, and poster. Therefor, further health education should be promoted via television. Periodic researches like knowledge, attitude, and practice studies can contribute to the understanding alluded to above. KAP studies are highly focused evaluations that estimate changes in human knowledge, attitude and practices in response to specific intervention, demonstration, education or circumstances (Shah et al., 2011). Here we present a correlation between knowledge, attitude, and practice was reveals that knowledge was statistical significant associated to attitude and practice, and attitude was statistical significant associated to practice. From this data indicates that decrease the liver fluke infection in this area should be health education approaches improve people knowledge and attitude that may affect to increase good practice of them.

In conclusion, the behavioral rate of liver fluke of participants was relatively high, and the formation rates of health behaviors and right attitude were relatively high. In addition, nurse and television are the main resources for a key success to increase people perceive of disease prevention and control in this area.

\section{Acknowledgements}

This work was supported by Suranaree University of Technology (SUT) and by Office of the Higher Education Commission under NRU Project of Thailand. Some part of this work was supported by the National Health Security Office of Nakhon Ratchasima province, through health promotion and prevention fund, year 2015. Special thanks all staffs of district public health organization of Chum Phuang for their assistance.

\section{References}

Best JW (1977). Research in education ( $3^{\text {rd }}$ ed). Englewood Cliffs, NJ: Prentice-Hall.

Bloom BS. (1971). Handbook on formative and summative of student learning. New York: Mc Graw-Hill Book Company.

Green A, Uttaravichien T, Bhudhisawasdi V, et al. (1991). Cholangiocarcinoma in northeast Thailand. A hospital-based study. Trop Geogr Med, 43, 193-8.

Harinasuta C, Vajrasthira S (1960). Opisthorchiasis in Thailand. Ann Trop Med Parasitol, 54, 100-05.

IARC. (1994). Infection with liver flukes (Opisthorchis viverrini, Opisthorchis felineus and Clonrochis sinensis). IARC Monogr Eval Carcinog Risks Hum, 61, 121-75.

Kaewkes S (2003). Taxonomy and biology of liver flukes. Acta Trop, 88, 177-86.

Kaewpitoon N, Kaewpitoon SJ, Pengsaa P, et al (2007). Knowledge, attitude and practice related to liver fluke infection in northeast Thailand. World J Gastroenterol, 13, 1837-40.

Kaewpitoon N, Kaewpitoon SJ, Pengsaa P(2008). Opisthorchiasis in Thailand: review and current status. World J Gastroenterol, 14, 2297-302.

Kaewpitoon N, Kaewpitoon SJ, Pengsaa P, et al (2008). Opisthorchis viverrini: the carcinogenic human liver fluke. World J Gastroenterol, 14, 666-74.

Kaewpitoon SJ, Kaewpitoon N, Rujirakul et al (2015). The carcinogenic liver fluke Opisthorchis viverrini among rural community people in northeast thailand: a cross- sectional descriptive study using multistage sampling technique. Asian Pac J Cancer Prev, 16, 7803-7.

Kaewpitoon N, Kootanavanichpong N, Kompor P, et al (2015). Review and current status of Opisthorchis viverrini infection at the community level in Thailand. Asian Pac J Cancer Prev, 16, 6825-30

Kaewpitoon SJ, Rujirakul R, Kaewpitoon N (2012). Prevalence of Opisthorchis viverrini infection in Nakhon Ratchasima province, Northeast Thailand. Asian Pac J Cancer Prev, 13, 5245-9.

Likert R (1932). A technique for the measurement of attitudes, Archives Psychol, 140, 44-53

Preuksaraj S, Jeeradit C, Satilthai A, et al (1982). Prevalence and intensity of intestinal helminthiasis in rural Thailand. Con Dis J, 8, 221-69.

Sadun EH (1955). Studies on Opisthorchis viverrini in Thailand. Am J Hyg, 62, 81-115.

Shah AP, Parmar SA, Ramkishan A, et al (2011). Knowledge, attitude and practice (KAP) survey regarding the safe use of medicines in rural area of Gujarat. Advance Tropical Medicine Public Health Int, 1, 66-70.

Shin HR, Oh JK, Masuyer E, et al (2010). Epidemiology of cholangiocarcinoma: an update focusing on risk factors. Cancer Sci, 101, 579-85.

Sithithaworn P, Andrews RH, Nguyen VD, et al (2012). The current status of opisthorchiasis and clonorchiasis in the Mekong Basin. Parasitol International, 61, 10-6.

Songserm N, Bureelerd O, Thongprung S, et al (2015). Community Participation in Cholangiocarcinoma Prevention in Ubon Ratchathani, Thailand: Relations with Age and Health Behavior. Asian Pac J Cancer Prev, 16, 7375-9.

Sripa B, Brindley PJ, Mulvenna J, et al (2012). The tumorigenic liver fluke Opisthorchis viverrini-multiple pathways to cancer. Trends Parasitol, 28, 395-407.

Sripa B, Kaewkes S, Intapan PM, et al (2010). Food-borne trematodiases in Southeast Asia: epidemiology, pathology, clinical manifestation and control. Adv Parasitol, 72, 305-50.

Sripa B, Kaewkes S, Sithithaworn P, et al (2007). Liver fluke 
Soraya J Kaewpitoon et al induces cholangiocarcinoma. PLoS Med, 4, 201.

Sripa B, Pairojkul C 2008. Cholangiocarcinoma: lessons from Thailand. Curr Opin Gastroenterol, 24, 349-56.

Sripa B, Tangkawattana S, Laha T, et al (2015). Toward integrated opisthorchiasis control in northeast Thailand: the Lawa project. Acta Trop, 141, 361-7.

Thamavit W, Bhamarapravati N, Sahaphong S, et al. (1978). Effects of dimethylnitrosamine on induction of cholangiocarcinoma in Opisthorchis viverrini-infected Syrian golden hamsters. Cancer Res, 38, 4634-9.

Wongba N, Thaewnongiew K, Phathee K, et al (2011). Liver fluke prevention and control in the northeast of Thailand through action research. Asian Pac J Cancer Prev, 12, 1367-70.

Wongsaroj T, Nithikathkul C, Rojkitikul W, et al (2014). National survey of helminthiasis in Thailand. Asian Biomedicine, $\mathbf{8}$, 779-83

Wykoff DE, Harinasuta C, Juttijutada P, Winn MM (1965). Opisthorchis viverrini in Thailand-the life cycle and comparison with O. felineus. J Parasitol, 51, 207-14. 